\title{
EDUCATION
}

\section{Progressing the action plan in Scotland - an educational perspective}

\author{
A. H. Forgie ${ }^{1}$
}

"The dental

action plan

has provided

Scotland

with the best

opportunity for modernising dental services

since the

NHS was

established."
${ }^{1 *}$ Associate Dean for

Postgraduate Dental Education,

NHS Education Scotland, 2nd

Floor Hanover Building, 66 Rose

Street, Edinburgh, EH2 2NN

*Correspondence to:

Dr Andrew Forgie

Email:andrew.forgie@nes.scot.

nhs.uk

In March 2005 the Scottish Executive Health Department published the 'Action plan for improving oral health and modernising NHS dental services in Scotland'. Six areas required major new educational input: pre-qualification education, workforce supply, career development, dental practice and team development, clinical effectiveness/quality improvement and support for the oral health strategy. Targets from the action plan that have been fully achieved include: 1) undergraduate student numbers have reached the target output of 135 per year; 2) vocational training numbers match graduate numbers; 3 ) a vocational training scheme for dental therapists has been developed and numbers of VT places will match the number of qualifying therapists; 4) a new strategy to support dental nurse training will allow an additional 200 dental nurse training places by 2007; and 5) a clinical effectiveness programme has developed a rolling programme of guidelines, the first one of which, on conscious sedation, was released in May. The dental action plan has provided Scotland with the best opportunity for modernising dental services since the NHS was established. This paper describes some of the educational developments that will ensure NHS dental services in Scotland are 'fit for the future' and 'delivering for health'.

\section{INTRODUCTION}

In March 2005 the Scottish Executive Health Department (SEHD) published the 'Action plan for improving oral health and modernising NHS dental services in Scotland.' ${ }^{1}$ The document outlines the Executive's plans for addressing Scotland's poor oral health record, providing better access to NHS dentistry for patients and for providing an attractive package for staff being recruited to or retained within the NHS in Scotland. SEHD has dedicated $£ 15$ million for education and training. NHS Education Scotland (NES) is a special health board that helps to provide better patient care by designing, commissioning, quality assuring and, where appropriate, providing education, training and lifelong learning for the NHS workforce in Scotland. The dental directorate of NES has been charged with taking forward the challenging educational implications of the dental action plan (DAP). This can be divided into six work streams:
1. Pre-qualification education
2. Workforce supply
3. Career development
4. Practice/team development
5. Clinical effectiveness/quality improvement
6. Support for the oral health strategy.

This paper will identify the progress made over the last year towards achieving the aims of the action plan from an educational perspective within these six work streams.

\section{PRE-QUALIFICATION EDUCATION}

To provide a long-term solution to the current workforce shortage the action plan has indicated that an increase of dental student numbers should occur. A target of 135 graduates per year was set and has been achieved for 2006 and will be significantly exceeded from 2008 onwards.

To assist the Universities with the increase in student numbers and to follow General Dental Council (GDC) recommendations, dental outreach is now established in seven sites and is being developed in more than 20 other centres throughout Scotland. This provides the students with valuable clinical experience outside a conventional University setting whilst providing NHS dental treatment to patients. It is hoped that these placements will also encourage new graduates to work in areas that have a dental workforce shortage.

In addition to the 'golden hellos' currently on offer to dentists starting work within the NHS in Scotland, dental students will soon be offered bursaries of up to $£ 16,000$ for a commitment to working within the NHS in Scotland for five years following graduation.

Through NES, the SEHD is funding additional training places for dental therapists. The output of therapists will steadily build to 45 by 2010 . The increase in the numbers of therapists is being achieved by adopting a flexible approach that will offer learners and the service a range of opportunities in a variety of settings (Glasgow, Dundee, Edinburgh, Dumfries ${ }^{1}$ and Inverness $\left.{ }^{1}\right)^{*}$.

This year the GDC has, for the first time, introduced *subject to GDC approval 
mandatory registration for all dental nurses. Dental nurses require a registrable qualification or to be in training. A new strategy to support basic nurse training has been approved by the NES Board. This strategy along with a significant investment in regional infrastructure will allow an additional 200 dental nurse training places to be delivered by 2007 .

\section{WORKFORCE SUPPLY}

To address short-term workforce shortages, forty dentists from Poland have been recruited. The first cohort is already working within the NHS in Scotland. NES has developed an educational programme that meets the individual needs of this group of dentists from both a professional and NHS organisational perspective. Mentorship arrangements are being put in place to support the new recruits.

Vocational training numbers have been increased to match graduate numbers. In recent years the percentage of graduates from the two Scottish dental schools who undertake vocational training in Scotland has increased from 52\% in 1999 to $84 \%$ in 2005. An allowance of $£ 3,000$ ( $€ 6,000$ if in a designated area) is paid to newly qualified dentists undertaking vocational training. This has occurred at the same time as more rigorous evaluation of the vocational trainees' progress has been developed. NES has recruited a record number of vocational trainers for year 2006/7.

In addition to these dental VT places, 10 additional places for new graduates have been established in the dental hospitals. These new foundation year one posts will bring the number of posts for graduates to 165 and pave the way for Scotland to move to two year foundation programmes in a phased manner. Currently NES offers two-year training programmes for about one third of the output of the dental schools in Scotland. This dental initiative will match the move to foundation programmes in medicine and the numbers are set at a level required to meet the long term targets for dental school output and the needs of NHS Scotland.

The first vocational training scheme for dental therapists has been developed in the West of Scotland with funding for numbers to match the number of new therapists being trained. The first trainees are now in post and two are in remote and rural areas.

\section{CAREER DEVELOPMENT}

In 2005/06 NES provided 453 courses for primary care dentists and 162 courses for other members of the dental team which can now be booked online. Some courses are relayed to northern locations via videoconferencing from a base in Inverness. This provision will be strengthened by 2007/08 when state of the art education and training facilities open in Inverness, Aberdeen and Dumfries. These capital developments will incorporate enhanced facilities for information technology, clinical skills and videoconferencing.

E-learning is a rapidly developing topic and NES has sought the views of general dental practitioners towards computer technology and learning in dentistry. This understanding along with a wider NES review of e-learning will shape future developments. The SEHD has committed itself to providing a connection to the NHSnet for all NHS dental practices. This will allow practitioners and other members of the dental team to access regulatory and educational material as well as providing a means for peer communication.

NES has developed and funded the Scottish Dental Rural Fellowship training scheme. In a partnership arrangement with rural NHS Boards, this new initiative will support up to 12 young graduates to access three years of postgraduate training in the salaried dental service and, through day release, provides access to an MSc in Clinical Dentistry at Glasgow, Dundee or Edinburgh. The Fellowship will enable dentists to provide intermediate and higher levels of care in a rural or island setting as a salaried practitioner with one of the rural NHS Boards.

\section{PRACTICE/TEAM DEVELOPMENT}

A central theme of the 'Kerr report'2 and 'Delivering for health's is ensuring sustainable and safe local services designed or redesigned to meet local needs and expectations. One way in which the DAP addresses this issue is through support and development of dental practices and their teams. This work will, for those NHS practices who wish, offer a range of in-practice education and training events delivered along the lines of the general medical practice 'Time to learn' initiative. Working closely with NHS Quality Improvement Scotland, practices will be offered in-practice education for the whole team. Practices will receive mentoring visits, be recompensed for closing on up to eight afternoons per year and receive tailor made educational sessions around agreed priority issues such as decontamination, resuscitation and radiological protection. This work will be rolled out during 2006/07 and by the end of 2008 all NHS practices in Scotland will be offered this support.

NES has progressed this initiative by appointing additional GDP educators and specialist nurses to lead on the delivery of in-practice decontamination education.

\section{CLINICAL EFFECTIVENESS/OUALITY IMPROVEMENT}

The National Dental Advisory Committee has established a clinical effectiveness programme funded through NES which is developing a rolling programme of guidelines in a variety of priority areas. For the initial phase of the programme, guidance is being produced for care of children with dental caries, emergency dental services, oral health assessment, decontamination, drug prescribing, practice support manual and conscious sedation. For each topic, a working group has been established that includes membership from primary care practitioners and dental care professionals to ensure that the most relevant stakeholders have a voice in the guidance development process. 
Guidance in these seven priority areas will be published during the next 18 months, with the first one relating to conscious sedation published in May this year. New topics are being considered and all members of the dental team are invited to suggest topics to the clinical effectiveness programme team. Dissemination and implementation are critical in order to maximise the impact of the work. With this in mind, the programme is integrated within NES and is supported by the three Scottish dental hospitals/schools who have agreed to promote the incorporation of new guidance into their education and training programmes.

\section{SUPPORT FOR THE ORAL HEALTH STRATEGY}

As part of work designed to ensure that oral health is given more attention and a higher priority by families with children at risk of poor oral health, the role of dental health support workers (DHSW) is being evaluated. The pilot in the West of Scotland is focussing on children under three years of age, whilst the one in the East of Scotland is targeting pre-school and early primary school aged children. The training programme of the DHSW has gained accreditation from the Royal Society for the Promotion of Health. If successful, these initiatives will be rolled out across Scotland with NES taking responsibility for the education and training of the DHSWs.

The messages from guidelines and good practice publications are built into the continuing professional development courses for all members of the dental team that are co-ordinated by NES.

\section{CONCLUSIONS}

The DAP has provided Scotland with the best opportunity of modernising dental services since the NHS was established. This paper has summarised the progress made by NES in relation to the DAP targets it has been asked to deliver. It has been possible to make progress with this work because of the broad strategic nature of the DAP, which has built on work started in 2002. It has integrated new allowances with capital developments, workforce planning, workforce development and clinical priorities. The unprecedented capital development programme that is coming on stream this year will deliver major 'teach and treat' centres across Scotland that will have a significant impact on NES's ability to deliver education and training aspects of the DAP and will improve access to NHS dental services.

1. Scottish Executive. An action plan for improving oral health and modernising NHS dental services in Scotland. http://www.scotland. gov.uk/Resource/Doc/37428/0012526.pdf. Edinburgh: Scottish Executive, 2005

2. Scottish Executive. Building a Health Service fit for the future. A national framework for service change in the NHS in Scotland. http://www.scotland.gov.uk/Resource/Doc/924/0012113.pdf. Edinburgh: Scottish Executive, 2005.

3. Scottish Executive. Delivering for health. http://www.scotland. gov.uk/Resource/Doc/77843/0018803.pdf. Edinburgh: Scottish Executive, 2005. 